\title{
CENTER-Pivot-MOUnTED SENSING SYSTEM FOR MONITORING PLANT HEIGHT AND CANOPY TEMPERATURE
}

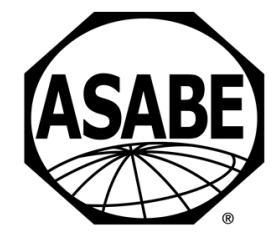

\author{
R. Sui, J. Baggard
}

\begin{abstract}
Easy-to-use data acquisition methods are required for variable-rate irrigation (VRI) decision support systems. Plant canopy temperature is related to plant water stress. Plant height is useful as an indicator of plant health conditions and can be used to estimate yield potential. Therefore, measurements of plant canopy temperature and plant height coupled with spatial information in the field can be used for determining VRI water application depths. A center-pivot-mounted wireless data acquisition (WDAQ) system was developed to collect plant canopy temperature and plant height data in the field. Each WDAQ unit consisted of a GPS receiver, programmable data logger, infrared temperature sensor, ultrasonic distance sensor, solar power supply, and wireless data transmitter/receiver. The system included two WDAQ units installed on a four-span center-pivot VRI system. One unit was mounted at the middle of the third span, and the other was mounted at the middle of the fourth span from the pivot. The infrared temperature sensors were used to detect the canopy temperature, while the ultrasonic distance sensors were used to measure plant height. The WDAQ system was designed to continuously and simultaneously measure plant canopy temperature and plant height and record the spatial coordinates at each measurement location as the center pivot moved around the field. Data collected were wirelessly transferred to a receiver for data processing. This WDAQ system has been tested and evaluated in the field for two years. Test results indicated that the WDAQ system was able to record approximately 3,200 measurements from each sensor in one pivot circle $\left(360^{\circ}\right)$. The measurement error of the ultrasonic distance sensor was 0.2 to $3 \mathrm{~cm}$ in a measurement range of 14 to $209 \mathrm{~cm}$, and the sensor-measured plant heights were strongly correlated with manually tape-measured plant heights in soybean and cotton crops $\left(r^{2}=0.97\right)$. Combined with the spatial information, measurements of plant height and crop canopy temperature were used to generate plant height and crop canopy temperature maps. Spatial variabilities of plant height and canopy temperature across the field could be identified from the maps and used in irrigation research. The WDAQ system has great potential for automatic creation of VRI prescription maps and plant-based irrigation scheduling.
\end{abstract}

Keywords. Canopy temperature, Irrigation scheduling, Plant height, Sensors, Variable-rate irrigation.

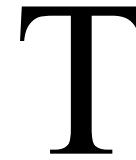
he Mid-South is a major crop production region in the U.S. The dominant crops grown in this region include corn, soybean, rice, and cotton. Soils in the Mid-South U.S., especially in the Mississippi Delta, are rich in nutrients. Soil variability is high, even within a single field (Cox et al., 2006; Thomasson et al., 2001), which results in differing storage capabilities and amounts of water available to crops. There is typically more than $100 \mathrm{~cm}$ of annual precipitation in the Mid-South, but the amount of rainfall in summer is often inadequate for high

\footnotetext{
cc) $(9) \Theta$ The authors have paid for open access for this article. This (C) ${ }_{\text {BY }}$ NC ND work is licensed under a Creative Commons AttributionNonCommercial-NoDerivatives 4.0 International License https:/creative commons.org/licenses/by-nc-nd/4.0/

Submitted for review in July 2017 as manuscript number ITSC 12506; approved for publication by the Information Technology, Sensors, \& Control Systems Community of ASABE in March 2018.

Mention of company or trade names is for description only and does not imply endorsement by the USDA. The USDA is an equal opportunity provider and employer.

The authors are Ruixiu Sui, Research Agricultural Engineer, and Jonnie Baggard, Engineering Technician, USDA-ARS Crop Production Systems Research Unit, Stoneville, Mississippi. Corresponding author: Ruixiu Sui, 141 Experiment Station Road, P.O. Box 350, Stoneville, MS 38776; phone: 662-686-5382; e-mail: ruixiu.sui@ars.usda.gov.
} 
location within a field according to a VRI prescription. Currently, VRI systems, including software tools for generating prescription maps, are commercially available for VRI practices. However, algorithms and models are required to determine the amount of water that needs to be applied based on the temporal and spatial variability of soil and plant characteristics.

While irrigation scheduling can be based on indirect plant stress measurements using soil water sensing devices and soil water balance calculations, direct plant stress monitoring is another method that has potential application for irrigation scheduling. With this method, irrigation scheduling can be based on physiological measurements and responses of the plants rather than on measurements of soil water status (Jones, 2004). Use of plant canopy temperature as an indicator of crop water stress is one of the plant-based methods for irrigation control. Thermal sensing technologies have been used as tools for water stress detection and irrigation scheduling (Jackson, 1986; Cohen et al., 2005; Evett et al., 1996; O'Shaughnessy and Evett, 2009). Portable infrared thermometers are capable of measuring small-scale canopy temperature with high spatial resolution, while thermal imagery is able to measure canopy temperature over large areas (Evans et al., 2000; Sadler et al., 2002; Bockhold et al., 2003; Sepulcre-Cantó et al., 2006). Most of the research involving the use of canopy temperature for irrigation scheduling has been performed in arid areas. The low vapor-pressure deficits that are characteristic of humid regions are reflected in smaller changes in the canopy-air temperature difference between stressed and non-stressed crops. It is thus necessary to conduct additional studies to determine the applicability and develop new methods for irrigation management using canopy temperature in humid regions.

Plant height is one of the key parameters to be considered in crop management. Plant height or plant growth rate could be used as an indicator of plant health status and yield potential (Sui and Thomasson, 2006; Yin et al., 2011, 2012; Sui, 2014). With an understanding of the relationship between plant height and production-related inputs, plant height could be useful information for predicting water needed by the crop.
VRI is an information-based technology. Various types of data are required to develop management zones and write VRI prescriptions. Sensors and sensor networks are useful tools for measuring plant and soil characteristics and other relevant parameters for VRI. Usually, the sensing device is installed above the ground surface at a specific point in the field to make the measurements. One of the issues with the installation of sensing devices in the field is the potential damage to the devices by agricultural equipment during field management practices such as fertilizer and chemical applications. The sensing device needs to be removed from the field or lowered to the ground to avoid this damage, which causes inconvenience for users and interruption of the data collection. Furthermore, due to cost constraints, only a limited number of sensing devices can be deployed in a field, which restricts the capacity for collecting data. In VRI management, it is necessary to have a data acquisition system that is able to support multi-type sensors to wirelessly and automatically scan the plant canopy, make non-contact measurements of parameters at numerous points across the field, and provide real-time in situ information for generating management zones and VRI prescriptions. The objective of this research was to develop a center-pivot-mounted wireless data acquisition system. As the pivot moves around the field, the system wirelessly and automatically measures plant height and plant canopy temperature along with spatial coordinates in real time in situ for VRI.

\section{Materials AND Methods}

\section{SySTEM DESCRIPTION}

A wireless data acquisition (WDAQ) system was built to perform real-time in situ measurements of plant height and plant canopy temperature for VRI. The WDAQ system was installed on a center-pivot irrigation system at the research farm of the USDA-ARS Crop Production Systems Research Unit at Stoneville, Mississippi $\left(33^{\circ} 26^{\prime} 30.86^{\prime \prime} \mathrm{N}, 90^{\circ} 53^{\prime}\right.$ $\left.26.60^{\prime \prime} \mathrm{W}\right)$. The system consisted of two separate units. Each unit included an ultrasonic distance sensor, an infrared temperature sensor, a data logger, a global position system (GPS)

Table 1. Details of the main parts of the WDAQ system.

\begin{tabular}{|c|c|c|c|}
\hline Part & Model & Main Specifications & Manufacturer \\
\hline $\begin{array}{l}\text { Ultrasonic distance } \\
\text { sensor }\end{array}$ & TSPC-30S1-232 & $\begin{array}{l}\text { Range: } 102 \mathrm{~mm} \text { to } 3 \mathrm{~m} \text {; Temperature: }-40^{\circ} \mathrm{C} \text { to } 70^{\circ} \mathrm{C} \text {; Humidity: } 0 \% \text { to } 100 \% \text {; Sensitiv- } \\
\text { ity/resolution: } 0.086 \mathrm{~mm} \text {; Repeatability: nominal } 0.2 \% \text { of range; Update rate: } 20 \mathrm{~Hz} \text {. }\end{array}$ & Senix \\
\hline $\begin{array}{l}\text { Infrared temperature } \\
\text { sensor }\end{array}$ & SI-111 & $\begin{array}{l}\text { Sensitivity: } 60 \mu \mathrm{V} \text { per }{ }^{\circ} \mathrm{C} \text {; Repeatability: }<0.05^{\circ} \mathrm{C} \text {; Field of view: } 22^{\circ} \text { half angle; Spec- } \\
\text { trum range: } 8 \text { to } 14 \mu \mathrm{m} \text {; Operating environment: }-55^{\circ} \mathrm{C} \text { to } 80^{\circ} \mathrm{C}, 0 \% \text { to } 100 \% \mathrm{RH} \text {. }\end{array}$ & $\begin{array}{c}\text { Apogee } \\
\text { Instruments }\end{array}$ \\
\hline Data logger & CR1000 & $\begin{array}{l}\text { Maximum scan rate: } 100 \mathrm{~Hz} \text {; Analog inputs: } 16 \text { single-ended or } 8 \text { differential individu- } \\
\text { ally configured; Digital ports: } 8 \text { I/Os or } 4 \text { RS-232; Communications ports: one CS I/O, } \\
\text { one RS-232, and one parallel peripheral; Power requirements: } 9.6 \text { to } 16 \text { VDC. }\end{array}$ & $\begin{array}{l}\text { Campbell } \\
\text { Scientific }\end{array}$ \\
\hline $\begin{array}{l}\text { Spread-spectrum } \\
\text { radio }\end{array}$ & RF401 & $\begin{array}{l}\text { Operating frequency: } 910 \text { to } 918 \mathrm{MHz} \text {; Type: frequency-hopping spread-spectrum } \\
\text { (FHSS) transceiver; RS-232 baud rate: } 38.4 \mathrm{k}, 19.2 \mathrm{k}, 9600,4800 \text {, or } 1200 \mathrm{bps} \text {; Receiver } \\
\text { sensitivity: }-110 \mathrm{dBm} \text { at } 10-4 \text { bit error rate; Transmitter output: } 100 \mathrm{~mW} \text { nominal. }\end{array}$ & $\begin{array}{l}\text { Campbell } \\
\text { Scientific }\end{array}$ \\
\hline $\begin{array}{l}\text { Spread-spectrum } \\
\text { radio }\end{array}$ & RF430 & $\begin{array}{l}\text { Operating frequency: } 910 \text { to } 918 \mathrm{MHz} \text {; Type: frequency-hopping spread-spectrum } \\
\text { (FHSS) transceiver; USB baud rate: } 38.4 \mathrm{k}, 19.2 \mathrm{k}, 9600,4800 \text {, or } 1200 \mathrm{bps} \text {; Receiver } \\
\text { sensitivity: }-110 \mathrm{dBm} \text { at } 10-4 \text { bit error rate; Transmitter output: } 100 \mathrm{~mW} \text { nominal. }\end{array}$ & $\begin{array}{l}\text { Campbell } \\
\text { Scientific }\end{array}$ \\
\hline GPS receiver & GPS16X-HVS & $\begin{array}{l}\text { Receiver: WAAS enabled; Baud rate: factory set to } 38.4 \mathrm{k} \text { bps; Update rate: program- } \\
\text { mable from } 1 \text { to } 900 \mathrm{~s} \text {; Operating temperature range: }-30^{\circ} \mathrm{C} \text { to } 80^{\circ} \mathrm{C} \text {; DGPS (WAAS) } \\
\text { correction: }<3 \mathrm{~m} \text {. }\end{array}$ & $\begin{array}{l}\text { Campbell } \\
\text { Scientific }\end{array}$ \\
\hline Solar panel & SP10 & Current at peak: $0.59 \mathrm{~A}$; Voltage at peak: $16.8 \mathrm{~V}$; Maximum peak power: $10 \mathrm{~W}$. & $\begin{array}{l}\text { Campbell } \\
\text { Scientific }\end{array}$ \\
\hline Rechargeable battery & PS100 & Power out: unregulated 12 VDC; Nominal rating: 7 Ah; Weight: $3.1 \mathrm{~kg}$. & $\begin{array}{l}\text { Campbell } \\
\text { Scientific }\end{array}$ \\
\hline
\end{tabular}




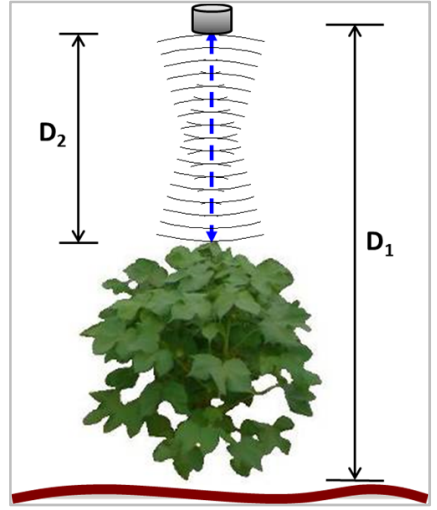

Figure 1. Plant height measurement using ultrasonic sensor.

receiver, a spread-spectrum radio, and a solar power supply. Table 1 lists the details of the main parts of the WDAQ system. The ultrasonic distance sensor was used to measure plant height. The infrared temperature sensor detected plant canopy temperature. The GPS receiver was used to determine the locations of the plant height and canopy temperature measurements. The WDAQ system was able to take simultaneous measurements of plant height, canopy temperature, and spatial coordinates of the measurement locations as the center pivot moved around the field. Data on the plant height and canopy temperature collected at each measurement point were wirelessly transmitted through the spread-spectrum radios and could be downloaded to a computer.

The ultrasonic distance sensor (TSPC-30S1-232, Senix, Hinesburg, Vt.) used to determine plant height was positioned on the pivot above the plant canopy. This sensor measured the distance between the sensor and the plant canopy. The plant height was calculated by subtracting the measured distance $\left(D_{2}\right)$ from the known distance between the ground surface and the sensor $\left(\mathrm{D}_{1}\right)$ (fig. 1). The infrared temperature sensor (SI111, Apogee Instruments, Logan, Utah) measured plant canopy temperature by converting the thermal energy radiated from the canopy in its field of view (FOV) to an electrical signal. The output of the infrared temperature sensor was directly wired to one input of the data logger.

\section{SYSTEM INSTALLATION}

The WDAQ system was installed on a four-span centerpivot VRI system with a lateral length of $233 \mathrm{~m}$. One unit (WDAQ-1) was installed in the middle of the third span, $140 \mathrm{~m}$ from the pivot, and the other unit (WDAQ-2) was installed in the middle of the fourth span, $199 \mathrm{~m}$ from the pivot (figs. 2 and 3). A triangular aluminum plate was mounted on the pivot's frame. The data logger box, GPS receiver, and solar panel were mounted on the aluminum plate. Square steel tubing was vertically fixed on the pivot's frame, and two mounting brackets were installed on the tubing. The ultrasonic distance sensor was placed on one mounting bracket, and the infrared temperature sensor was mounted on the other bracket. Both sensors were installed facing down toward the plant canopy. The distance between the sensors and the canopy could be adjusted by moving the brackets up and down along the square tubing. In field operation, the ultrasonic distance sensor was kept at least $0.2 \mathrm{~m}$ above the plant canopy, while the infrared temperature sensor was about $0.3 \mathrm{~m}$ above the canopy.

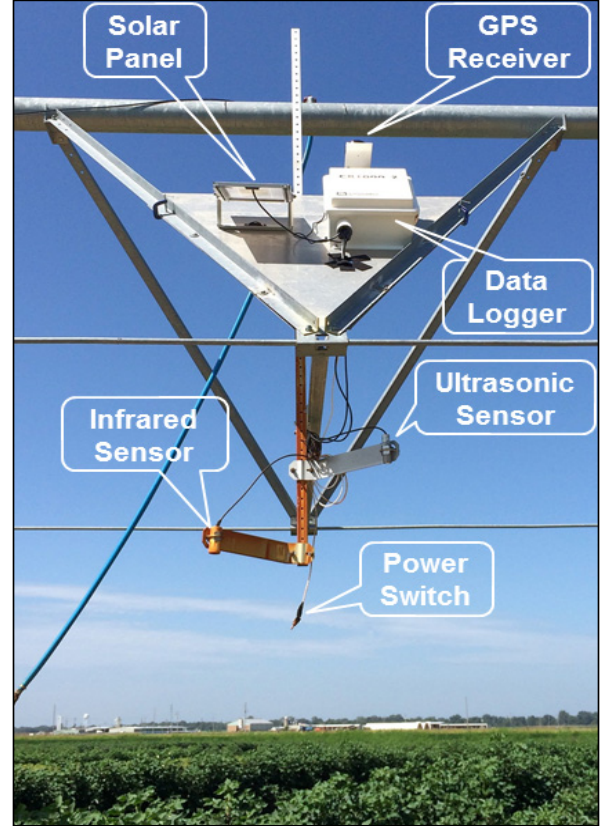

Figure 2. One unit of WDAQ system mounted on pivot frame.

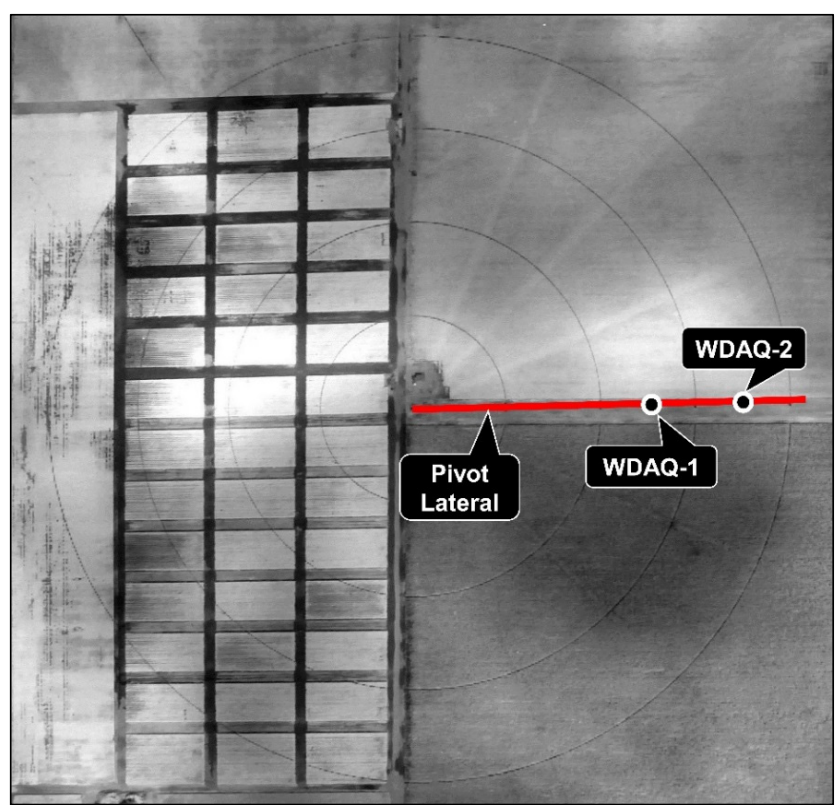

Figure 3. WDAQ units on third and fourth spans of pivot lateral.

\section{DATA ACQUisition}

The data logger (CR1000, Campbell Scientific, Logan, Utah) was used to collect data from the ultrasonic distance sensor, infrared temperature sensor, and GPS receiver. The data logger also connected with the RF401 spread-spectrum radio to allow wireless data transmission. The data logger had multiple ports for data input and output, including ana$\log$ inputs, digital I/Os, and communication ports. The data logger, spread-spectrum radio, and rechargeable battery were housed in a weatherproof enclosure. The WDAQ system was powered using the SP10 solar panel. The ultrasonic distance sensor and GPS receiver were respectively connected to two RS-232 ports of the data logger, while the infrared temperature sensor was connected to a differential 
analog input. As the center pivot moved around the field, the data logger collected data from the ultrasonic distance sensor, the infrared temperature sensor, and the GPS receiver. The data logger was programmed to make one round of data collection from the sensors in each second. Because the center pivot moved at a very slow speed, we chose to store and report the average measurements of the sensors at $10 \mathrm{~s}$ intervals to avoid collecting a large amount of data that might not be necessary for VRI practices. However, the time interval of data collection could be easily changed in the WDAQ system. All data collected were recorded in the data logger and transmitted to the RF401 spread-spectrum radio through a communication port of the data logger. The two RF401 radios in the WDAQ system transmitted the data wirelessly to the RF430 spread-spectrum radio. The data were downloaded to a computer through the USB port on the RF430 radio with $\mathrm{PC} 200 \mathrm{~W}$ software.

\section{SYSTEM TESTS}

The system was tested statically and dynamically. In the static tests, the WDAQ system measured the heights of objects including paper boxes, soybean plants, and cotton plants when the pivot was not moving. Measurements from the ultrasonic distance sensor were compared with manually tape-measured distances to determine the system accuracy. In the static tests with paper boxes, boxes of different heights were placed under the ultrasonic distance sensor. The heights of the boxes were measured using the WDAQ system and manually using a tape measure. The tests with soybean and cotton plants were conducted on August 31, 2015, in the field under the pivot. In these tests, the pivot was stopped at multiple locations in the field for the WDAQ to measure the plant height at each location. At the same locations, the plant heights from the ground surface to the topmost unfurled leaf in its natural position were manually measured using a tape measure.

The dynamic tests were conducted in the field with corn, soybean, and cotton crops in the 2015 and 2016 seasons. Under the center-pivot irrigation system, corn was planted in the sector between $0^{\circ}$ and $90^{\circ}$, soybean was planted between $90^{\circ}$ and $180^{\circ}$, irrigated cotton was planted between $180^{\circ}$ and $270^{\circ}$, and rainfed cotton was planted between $270^{\circ}$ and $360^{\circ}$ (fig. 3). Using the WDAQ system in 2015, the corn canopy was scanned for plant height and canopy temperature on June 11, which was 72 days after planting (DAP), and the soybean and cotton canopies were scanned on June 26, which was 50 and 42 DAP, respectively. In 2016, the corn, soybean, and cotton canopies were scanned at 55,42 , and 34 DAP, respectively.

In the dynamic tests, the ultrasonic sensors were set about $1 \mathrm{~m}$ higher than the canopy. The canopy temperature sensor was placed about $0.5 \mathrm{~m}$ above the canopy. Approximate 800 measurements were collected with each sensor in each $90^{\circ}$ sector, which is equivalent to $0.28 \mathrm{~m}$ per measurement with WDAQ-1 and $0.39 \mathrm{~m}$ per measurement with WDAQ-2.

\section{RESULTS AND DISCUSSION}

The sensor-measured heights were compared with the manually tape-measured heights. Static test results of the box height measurements are shown in table 2. The WDAQmeasured heights were very close to the manually tapemeasured heights. The measurement error varied from 0.2 to $3 \mathrm{~cm}$ in a measurement range from 14 to $209 \mathrm{~cm}$. Figure 4

Table 2. Comparison of WDAQ-measured box heights with manually tape-measured box heights.

\begin{tabular}{cccc}
\hline & \multicolumn{2}{c}{ Measurement $(\mathrm{cm})$} & $\begin{array}{c}\text { Error } \\
(\mathrm{cm})\end{array}$ \\
\cline { 2 - 3 } Run & Sensor & Tape & 0.2 \\
2 & 14.1 & 14.3 & 1.0 \\
3 & 42.8 & 43.8 & 1.3 \\
4 & 72.0 & 73.3 & 1.2 \\
5 & 101.7 & 102.9 & 1.3 \\
6 & 122.8 & 124.1 & 1.6 \\
7 & 149.2 & 150.8 & 1.5 \\
8 & 173.4 & 174.9 & 1.6 \\
9 & 175.9 & 177.5 & 1.9 \\
10 & 201.0 & 202.9 & 3.0 \\
\hline
\end{tabular}

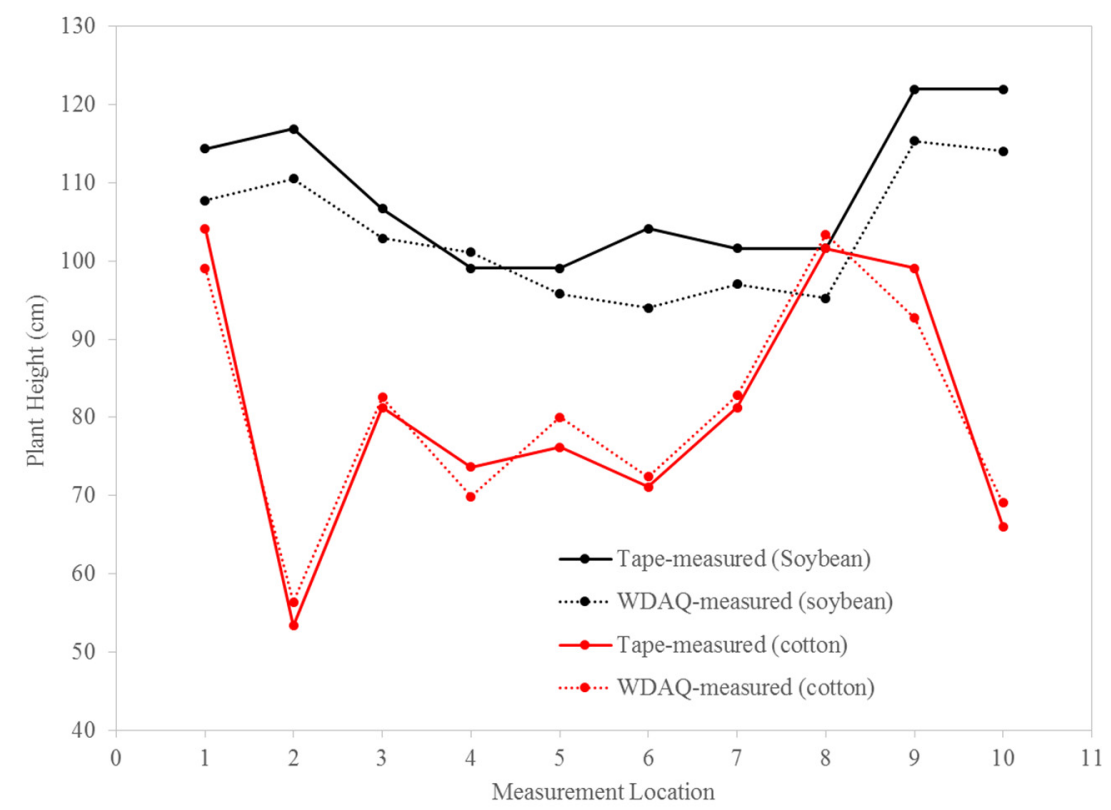

Figure 4. WDAQ-measured plant heights of soybean and cotton compared with tape-measured plant heights in the static tests. 
shows the static test results of plant height measurements for soybean and cotton. For soybean plants, the average absolute measurement error was $5.8 \mathrm{~cm}$ in a measurement range from 99.1 to $121.9 \mathrm{~cm}$. It is notable that all of the soybean plant heights, except one in location 4 , were underestimated by the WDAQ system. For cotton plants, the average absolute measurement error was $3.1 \mathrm{~cm}$ in a measurement range from 66.0 to $104.1 \mathrm{~cm}$. Figure 5 shows the linear relationship between plant heights measured by the WDAQ system and with the tape measure for soybean and cotton. The WDAQ measurements are strongly correlated with the manual measurements $\left(r^{2}=0.97\right)$.

The underestimation of soybean height by the WDAQ system could be attributed to misalignment between the ultrasonic sensor and the highest point of the measured plant. The ultrasonic sensor measured the distance from the sensor to the closest plant leaf in the canopy. If the closest leaf under the sensor's field of view was not the highest point of the plant, the plant height would be underestimated by the WDAQ system. When the tests were conducted, the soybean plants were at the R5 growth stage. The plant leaves started shedding, and the plant canopy was not closed well. This could have caused the sensor-measured distance between the sensor and the canopy $\left(D_{2}\right.$ in fig. 1$)$ to be greater than the actual distance; as a result, the sensor-measured plant height was less than the manually tape-measured plant height. However, the cotton canopy was well closed during the tests. In comparison to the soybean height measurements, the cotton heights measured by the WDAQ system were closer to the manually tape-measured values, and the measurement errors were distributed in a random pattern. Additionally, plant movement caused by wind could be another source of error in the WDAQ system measurements. The cotton plants moved less than the soybean plants.

The WDAQ system recorded about 3,200 measurement points from each sensor in one pivot circle $\left(360^{\circ}\right)$. Figures 6 and 7 are plant height and canopy temperature maps that were generated using the data collected by the WDAQ system. From the plant height maps, it is obvious the system was able to determine the variation in plant height among crops and within a crop. At the time when the crops were scanned, the corn crop was tallest, the cotton crop was shortest, and the soybean crop height was between corn and cotton. The differences in canopy temperature are clearly indicated in the canopy temperature maps. Taking the canopy temperature map in the soybean and cotton crops on June 26, 2015 , as an example (fig. 6b), the canopy temperature of the irrigated cotton crop was lower than that of the non-irrigated crop, and the canopy temperature of the soybean crop was lower than that of irrigated cotton. Variabilities in canopy temperature within the rainfed cotton, irrigated cotton, and soybean crops are clearly shown in the map as well. The variabilities in plant height and canopy temperature within each crop were caused by multiple parameters, such as irrigation rate, fertilization rate, and soil properties. Analyses of plant height and canopy temperature for use in VRI and precision crop management will be reported in separate articles. This article focuses on the concept, design, prototype fabrication, and preliminary tests of the WDAQ system.

VRI systems are commercially available. VRI practice requires VRI prescription maps that include the spatial coordinates of each management zone and the irrigation depth associated with each management zone. The VRI system delivers water to the management zones according to the prescription maps. A prescription map can be created using the software associated with the VRI system. However, to generate the prescription map, algorithms must be used to calculate the amount of water needed at each location in the field. Currently, a lack of these algorithms is the great challenge in VRI development. Multiple inputs, including soil properties, plant water stress, crop yield potential, field topography, and other relevant parameters, could be used to

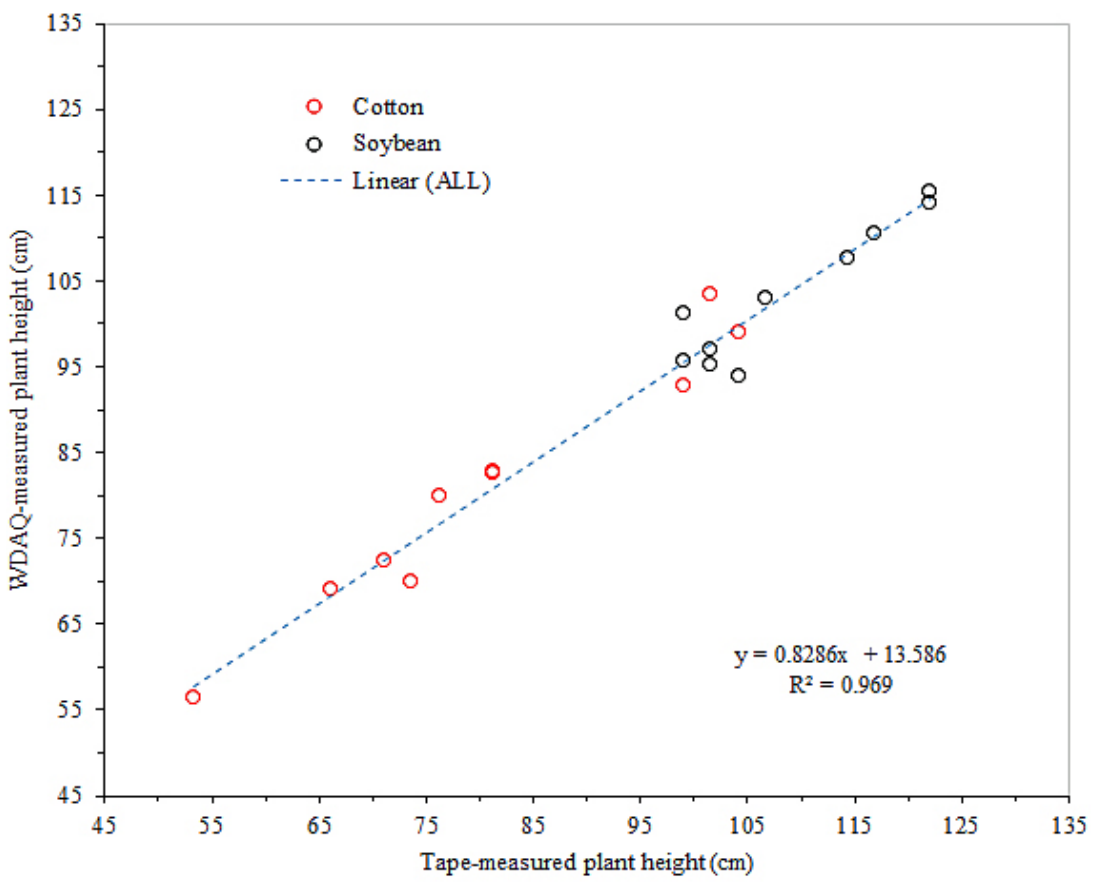

Figure 5. Sensor-measured plant height versus tape-measured plant height. 


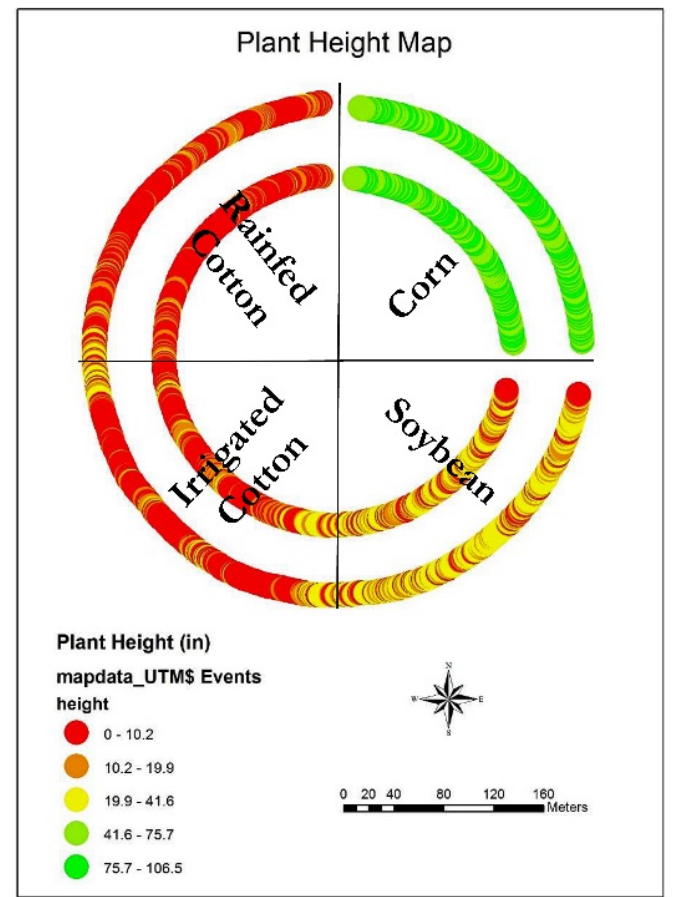

(a)

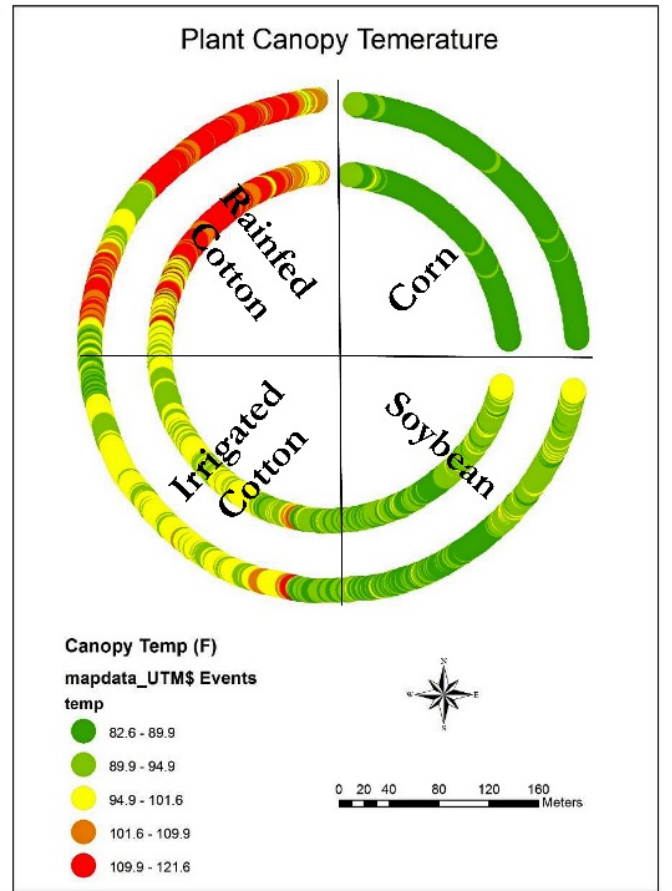

(b)

Figure 6. Maps of (a) plant height and (b) canopy temperature from data collected by the WDAQ system. Corn was scanned on June 11, 2015, and soybean and cotton were scanned on June 26, 2015.

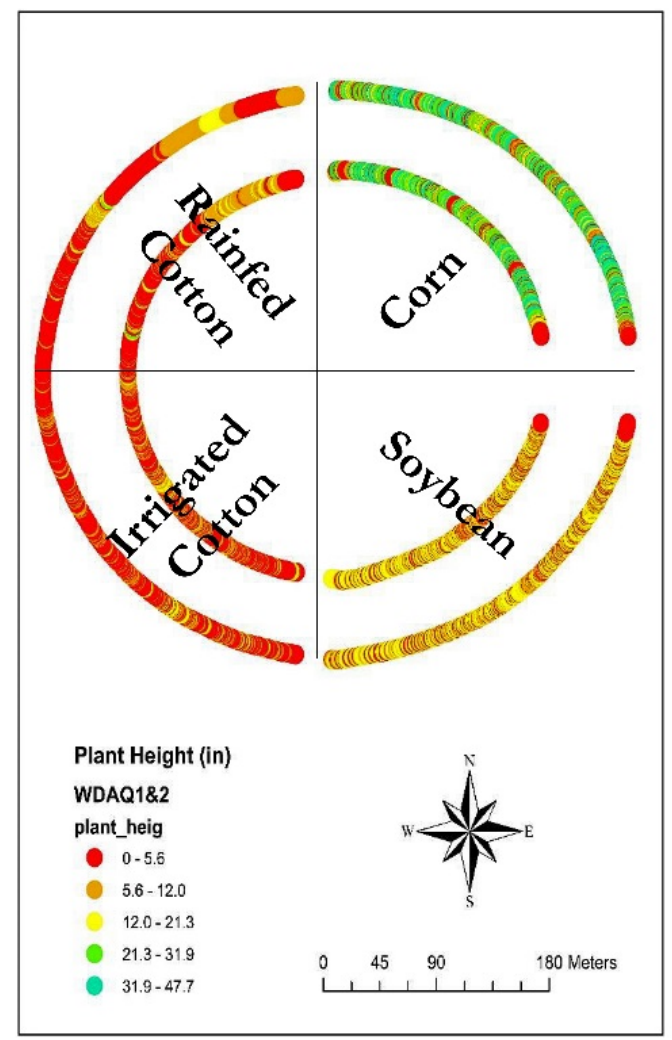

(a)

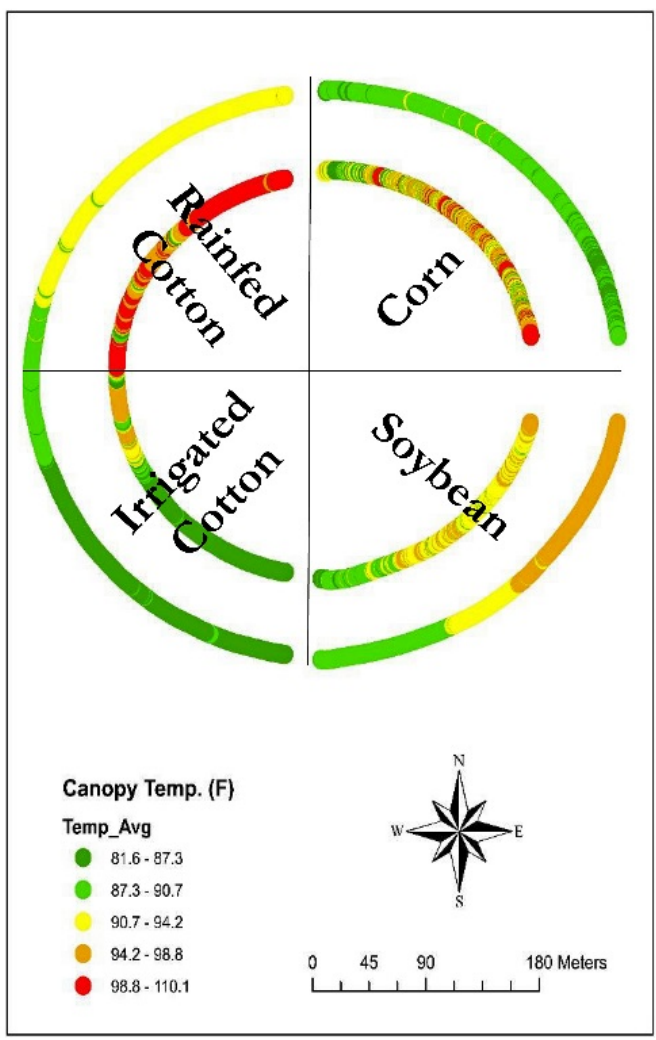

(b)

Figure 7. Maps of (a) plant height and (b) canopy temperature from data collected by the WDAQ system. Corn, soybean, and cotton were scanned on May 23, June 6, and June 7, 2016, respectively.

delineate management zones and determine the irrigation application rate. Previous studies showed that crop canopy temperature could be used to indicate plant water stress, and

plant height was correlated with crop yield potential. Therefore, the canopy temperature and plant height data collected by the WDAQ system can be used as inputs to develop VRI 
algorithms or used directly as input parameters in an algorithm to generate VRI prescription maps.

The data loggers used in the WDAQ system have more inputs available. By adding other types of sensors to the inputs, the WDAQ system can be easily expanded to measure more parameters in the field. For example, crop canopy spectral reflectance can be collected by adding spectral reflectance sensors. Soil moisture data from wireless soil moisture sensors installed in multiple locations in the field can be collected by adding a wireless module.

\section{CONCLUSION}

Variable-rate irrigation (VRI) needs decision support systems to determine water application depths at site-specific locations within a field. Plant characteristics such as crop canopy temperature and plant height could be used in diagnosing plant water stress and estimating plant water needs. A wireless data acquisition (WDAQ) system was developed to measure the plant height and crop canopy temperature. The WDAQ system consisted of ultrasonic distance sensors, infrared temperature sensors, GPS receivers, and wireless data radios. It was installed on a four-span center-pivot VRI system. Measurement error of the ultrasonic sensor was 0.2 to $3 \mathrm{~cm}$ in a measurement range from 14 to $209 \mathrm{~cm}$, and the sensor-measured plant heights were strongly correlated with manually tape-measured plant heights of soybean and cotton crops $\left(r^{2}=0.97\right)$. Field tests in two years showed that the WDAQ system was able to scan the plant canopy and record approximately 3,200 non-contact measurements from each sensor as the center pivot moved in a full circle around the field. The plant height and canopy temperature measurements, along with their spatial coordinates, were used to generate plant height and canopy temperature maps for VRI research.

The lack of effective methods to create VRI prescriptions using information from various sensors and the insufficiency of evidence to prove the advantages of VRI practice have hindered the development and adoption of VRI technologies. This WDAQ system uses a center-pivot VRI system as the platform for real-time in situ measurements of plant characteristics across different irrigation management zones within a field. The data collected by this system could be used to investigate plant responses to water stress and develop algorithms for VRI and irrigation automation. More field tests will be conducted to systematically evaluate the performance of this WDAQ system, and the system will be upgraded by adding more sensors to measure more plant characteristics, including plant canopy spectral reflectance.

\section{REFERENCES}

Bockhold, D. L., Thompson, A. L., Sudduth, K. A., \& Henggeler, J. C. (2011). Irrigation scheduling based on crop canopy temperature for humid environments. Trans. ASABE, 54(6), 2021-2028. https://doi.org/10.13031/2013.40654

Cohen, Y., Alchanatis, V., Meron, M., Saranga, Y., \& Tsipris, J. (2005). Estimation of leaf water potential by thermal imagery and spatial analysis. J. Exp. Bot., 56(417), 1843-1852. https://doi.org/10.1093/jxb/eri174

Cox, M. S., Gerard, P. D., \& Abshire, M. J. (2006). Selected soil properties' variability and their relationships with yield in three Mississippi fields. Soil Sci., 171(7), 541-551. https://doi.org/10.1097/01.ss.0000228031.49776.0f

Evans, D. E., Sadler, E. J., Camp, C. R., \& Millen, J. A. (2000). Spatial canopy temperature measurements using center pivot mounted IRTs. Proc. 5th Intl. Conf. on Precision Agriculture. St. Paul, MN: University of Minnesota, Precision Agriculture Center.

Evett, S. R., Howell, T. A., Schneider, A. D., Upchurch, D. R., \& Wanjura, D. F. (1996). Canopy temperature based automatic irrigation control. In C. R. Camp, E. J. Sadler, \& R. E. Yoder (Eds.), Proc. Intl. Conf. on Evapotranspiration and Irrigation Scheduling (pp. 207-213). St. Joseph, MI: ASAE.

Jackson, R. D. (1986). Remote sensing of biotic and abiotic plant stress. Ann. Rev. Phytopathol., 24(1), 265-287. https://doi.org/10.1146/annurev.py.24.090186.001405

Jones, H. G. (2004). Irrigation scheduling: advantages and pitfalls of plant-based methods. J. Exp. Botany, 55(407), 2427-2436. https://doi.org/10.1093/jxb/erh213

O'Shaughnessy, S. A., \& Evett, S. R. (2010). Canopy temperature based system effectively schedules and controls center pivot irrigation of cotton. Agric. Water Mgmt., 97(9), 1310-1316. https://doi.org/10.1016/j.agwat.2010.03.012

Sadler, E. J., Camp, C. R., Evans, D. E., \& Millen, J. A. (2002). Corn canopy temperatures measured with a moving infrared thermometer array. Trans. ASAE, 45(3), 581-591. https://doi.org/10.13031/2013.8855

Sepulcre-Cantó, G., Zarco-Tejada, P. J., Jiménez-Muñoz, J. C., Sobrino, J. A., de Miguel, E, \& Villalobos, F. J. (2006).

Detection of water stress in an olive orchard with thermal remote sensing imagery. Agric. Forest Meteorol., 136(1), 31-44. https://doi.org/10.1016/j.agrformet.2006.01.008

Sui, R. (2014). Three-year study on plant height mapping. Proc. Beltwide Cotton Conf. Memphis, TN: National Cotton Council.

Sui, R., \& Thomasson, J. A. (2006). Ground-based sensing system for cotton nitrogen status determination. Trans. ASABE, 49(6), 1983-1991. https://doi.org/10.13031/2013.22279

Thomasson, J. A., Sui, R., Cox, M. S., \& Al-Rajehy, A. (2001). Soil reflectance sensing for determining soil properties in precision agriculture. Trans. ASAE, 44(6), 1445-1453. https://doi.org/10.13031/2013.7002

Yin, X., Hayes, R. M., McClure, M. A., \& Savoy, H. J. (2012). Assessment of plant biomass and nitrogen nutrition with plant height in early- to mid-season corn. J. Sci. Food Agric., 92(13), 2611-2617. https://doi.org/10.1002/jsfa.5700

Yin, X., McClure, M. A., Jaja, N., Tyler, D. D., \& Hayes, R. M. (2011). In-season prediction of corn yield using plant height under major production systems. Agron. J., 103(3), 923-929. https://doi.org/10.2134/agronj2010.0450 